Trascender, Contabilidad y Gestión. Vol. 6, Núm. 18 (septiembre - diciembre del 2021).

Universidad de Sonora. Departamento de Contabilidad. México.

ISSN: 2448-6388. Reserva de Derechos 04-2015-04172070800-203.

\title{
Análisis de los tipos de cambio USDMXN, GBPMXN, EURMXN usando RSI y Osciladores Estocásticos durante la pandemia del COVID19
}

\author{
Exchange rate analysis USDMXN, GBPMXN, EURMXN using RSI and Stochastic \\ Oscillators during the COVID19 pandemic
}

José Miguel Mata Hernández ${ }^{1}$; Arturo Morales Castro ${ }^{2}$

Recibido: 5 de abril de 2021.

Aceptado: 9 de junio de 2021.

DOI: https://doi.org/10.36791/tcg.v0i18.125

JEL: E44. Mercados financieros y macroeconomía.

G19. Generalidades, economía financiera.

O24. Política de tipo de cambio.

\section{Resumen}

El uso de herramientas de análisis técnico como el índice de fuerza relativa (Wilder, 1978) y los osciladores estocásticos en sus versiones de rápido y lento (Lane, 1984), pueden servir al inversionista para una mejor toma de decisiones para realizar operaciones de inversión. El COVID19 tuvo un impacto en los mercados financieros, un mercado que se vio muy afectado fue el mercado de divisas, en donde los tipos de cambio del peso mexicano presentaron una fluctuación y volatilidad debido a los

\footnotetext{
${ }^{1}$ José Miguel Mata Hernández. Licenciado en Negocios y Comercio Internacional. Especialidad en Gestión de Riesgos Financieros y Empresariales. Especialidad en tráfico y tramitación de mercancías. Certificación como Analista de Capitales y Valores por Corporate Finance Institute. Maestría en Finanzas Bursátiles. Becario de investigación en Posgrado de la Facultad de Contaduría y Administración UNAM. Correo: josemiguelmata@hotmail.com. ORCID: https://orcid.org/0000-0003-0132-6881

${ }^{2}$ Arturo Morales Castro. Licenciado en Economía. Maestro en Finanzas, y Doctor en Ciencias de la Administración. Posdoctorado en la Universidad Autónoma del Estado de México. Profesor investigador. Facultad de Contaduría y Administración de la Universidad Nacional Autónoma de México. Correo: amorales@fca.unam.mx. ORCID: https://orcid.org/0000-0002-3159-5057
} 
efectos de la pandemia como por otras cuestiones durante el 2020. El uso de estos indicadores permitió visualizar los movimientos que hicieron lo pares de divisa de USDMXN, EURMXN y GBPMXN durante la pandemia y como con el uso de estas herramientas se pudieron haber tomado decisiones.

Palabras clave: Mercado de divisas, índice de fuerza relativa, osciladores estocásticos.

\begin{abstract}
The use of technical analysis tools such as the relative strength index (Wilder, 1978) and stochastic oscillators in their versions of fast and slow (Lane, 1984), can serve the investor for better decision making to make investment operations. COVID19 had an impact on the financial markets, a market that was badly affected, was the foreign exchange market, where the exchange rates of the Mexican peso presented a fluctuation and volatility due to the effects of the pandemic as for other issues during 2020. The use of these indicators allowed to visualize the movements that made the currency pairs of USDMXN, EURMXN and GBPMXN during the pandemic and how with the use of these tools, decisions could have been made.
\end{abstract}

Keywords: Forex, relative strength index, stochastic oscillators.

\section{Introducción}

El COVID19 ha provocado un gran golpe en las economías de muchos países del mundo, pero también los efectos que ha ocasionado en los mercados financieros fueron relevantes. Desde el reconocimiento de la enfermedad en Wuhan, China, se empezaron a ver los efectos que tenía esta misma, la forma en que empezó a tomar medidas China tuvo un efecto en su propia economía, así como en su divisa el Yuan y también en su nivel de exportaciones. Con el paso de las semanas y la declaración de la epidemia, se pudieron ver las consecuencias que traía esta enfermedad, aumentando el número de casos en el continente asiático, asimismo afectando a otras economías, por lo cual, los gobiernos de diversos países asiáticos empezaron a tomar medidas sanitarias. La Organización Mundial de la Salud declaró la enfermedad como pandemia el 11 de marzo de 2020, esto debido a que la misma enfermedad ya estaba presente en varios continentes, donde ya se habían presentado casos de contagios en Europa, en Oceanía y en África. En Estados Unidos apenas a principios de febrero del 2020 se empezaban a presentar los contagios y a finales del mes de febrero se presentaron los primeros contagios en México, a los pocos días el gobierno de mexicano determinó tomar la cuarentena y realizar el cierre industrial.

Los efectos por el cierre industrial como explica Preciado (2020), tuvieron un gran impacto en la economía mexicana, especialmente esto se vio en el Producto Interno Bruto y en el Producto Nacional Bruto, donde el PIB en los dos primeros trimestres fueron negativos, para el primer trimestre fue de $-1.2 \%$ y para el segundo trimestre fue de $-17.1 \%$, donde los efectos del cierre industrial y la pandemia del COVID19 tuvieron que ver con esos resultados, ya para el tercer trimestre del 2020 los resultados del PIB fueron positivos con $12 \%$, esto a causa de la reapertura de la economía.

La volatilidad está presente en los mercados financieros, en unos más que en otros, esto porque no se presenta al mismo nivel de fluctuación del precio de un activo en el mercado de capitales comparándolo con uno del mercado de divisas. En el 2020, la volatilidad estuvo 
presente en los mercados, esto debido a diversas causas relacionadas con variables macroeconómicas como otras determinantes, en donde fueron visibles estos efectos en los tipos de cambio. No todas las determinantes de carácter macroeconómico, noticas y aspectos tienen el mismo impacto en todos los mercados financieros. Los pares de divisas considerados exóticos son aquellos pares de divisas que no tienen un nivel de negociación o de liquidez tan amplio como los pares de divisas principales o los pares de divisas menores, algunos ejemplos de pares de divisas exóticos son dólar-peso mexicano, dólar-rand sudafricano, euro-peso mexicano, dólar-corona sueca.

Para objeto de este trabajo de investigación, se utilizaron las herramientas del índice de fuerza relativa conocido en inglés como Relative Strength Index y el oscilador estocástico, conocido en inglés como stochastic oscillator, esto con el fin de demostrar que, con el uso de estas herramientas pertenecientes al análisis técnico se pueden tomar decisiones para realizar operaciones de compra o venta de los activos estudiados; así como mostrar que los activos estudiados reflejaban posibilidades de realizar movimientos volátiles. Si bien, estas dos herramientas fungen principalmente para poder hacer una visualización de hacia donde se podría dirigir el precio de un activo financiero, también sirven para realizar un análisis de la sobre compra y sobre venta para así poder tener una mejor perspectiva de que movimientos podría hacer el precio del activo financiero estudiado.

Para efectos del trabajo de investigación se usaron los tipos de cambio SPOT de los tres pares de divisa con el peso mexicano que son USDMXN, EURMXN, GBPMXN, al igual que la cotización de los futuros del peso mexicano, los cuales se obtuvieron en la base de datos de Yahoo Finance.

De acuerdo con Serrano (2019), el análisis técnico es el estudio de la acción del mercado, donde se busca pronosticar la evolución del precio de un activo financiero a través del uso de gráficos y herramientas. Es por ello por lo que el uso de herramientas del análisis técnico como las plasmadas en la presente investigación, le pueden servir al inversionista para llegar a realizar una mejor toma de decisiones.

Ante una volatilidad en los tipos de cambio, existen medidas que sirven para contrarrestar los riesgos que implicar el realizar operaciones con los pares de divisa, esto se puede efectuar mediante el uso de derivados financieros. El MexDer en el 2020 presentó gran número de contratos de derivados efectuados entre los meses de marzo a junio, donde los contratos de futuros sobre divisas fueron los más negociados siguiéndole los del Índice de precios y cotizaciones de la Bolsa Mexicana de Valores.

La presente investigación cuenta con una introducción, objetivos, cuerpo del trabajo, resultados, discusión y fuentes de referencia.

\section{Objetivos}

El objetivo principal de la presente investigación es el demostrar que con el uso de indicadores que se usan dentro del análisis técnico de los mercados financieros, puede servir para observar una posibilidad hacia donde se podría dirigir el precio del activo. Estos mismos indicadores son muy usados dentro de los análisis de los mercados por lo cual pueden brindar un mayor panorama de que pudiese y que movimientos podría hacer el activo, para así llegar una mejor toma de decisiones. 


\section{Reflexiones sobre la Hipótesis sobre mercados}

De acuerdo con la teoría de mercados eficientes (Fama, 1960) considera que cualquier noticia o evento puede afectar a la cotización de un activo, por lo que hace que el precio se ajuste tan rápido, que sea imposible obtener un beneficio económico del mismo. En esta teoría también entran los principales intermediarios de un mercado, los cuales son los que tienen el capital suficiente para realizar operaciones mucho mayores que los pequeños inversionistas, tal es el nivel que estos mismos pueden manipular el precio de ciertos activos y crear fluctuaciones grandes en el precio.

Un mercado eficiente de acuerdo con Fama (1960), es aquel en el cual hay un número grande de participantes que maximizan ganancias racionales compitiendo de forma activa, donde cada uno de estos busca predecir los valores individuales futuros del mercado y donde la información presente se encuentra casi totalmente disponible para todos los participantes del mercado.

El mercado ideal de acuerdo con Malkiel y Fama (1970) es aquel en el que los precios proporcionan señales precisas para la asignación de los recursos. Por lo que, en un mercado en donde los precios siempre reflejen toda la información disponible se denomina eficiente.

Malkiel (2003) critica la teoría de los mercados eficiente de Eugene Fama, donde comenta que los elementos psicológicos y conductuales tienden a influir en la determinación de los precios de los activos financieros. Por otra parte, Shleifer (2000) menciona que las finanzas conductuales tienen un efecto importante en los mercados financieros, en donde los mismos participantes realizan sus decisiones de inversión a causa de como perciben el mercado, de sus emociones, como de acontecimientos que puedan provocar el movimiento del precio de un activo.

Shleifer (2000) comenta que los mercados financieros no se mueven de forma eficiente y no se mueven de la misma forma histórica como se cree, es decir la historia que se presenta en los precios no se presenta de la misma manera, un ejemplo muy claro se puede observar en el comportamiento ocurrido por la crisis económica y el h1n1 con respecto a lo ocurrido por lo acontecido por el COVID19, donde también hubieron implicaciones de las amenazas de guerra comercial con china, el posible conflicto bélico entre Estados Unidos e Irán y lo acontecido por la Organización de Países Exportadores de Petróleo.

El impacto en la economía mexicana que ha tenido la pandemia ha sido relevante, pero no solo esta ha sido afectada, sino también el mercado cambiario de divisas se vio muy afectado por la pandemia y otros acontecimientos que incrementaron la volatilidad.

\section{Análisis macroeconómico de los tipos de cambio.}

El rango dentro de la estructura de mercado dentro de los gráficos de un activo financiero se entiende como aquel movimiento del precio donde hay indecisión por parte de compradores y vendedores, es decir no muestra una tendencia clara ya sea bajista o alcista, este escenario se mostró entre 2018 al 2020 antes de la pandemia, donde el tipo de cambio del peso mexicano contra el dólar no tuvo una gran variación en su precio. En 2019, el tipo de cambio spot del dólar peso mexicano llegó a cotizar en \$19.7, donde también su precio más bajo en el 2019 fue en el punto de \$18.75 y el punto más alto fue dentro de los \$20.14. Para el caso del tipo de cambio de la libra esterlina durante el 2019, el precio más alto que alcanzó fue $\$ 25$ y su precio más bajo fue $\$ 23.19$. En cambio, en el caso del tipo de cambio del 
euro-peso mexicano durante el 2019, el precio más alto que alcanzó fue \$22.52 y su precio más bajo fue \$20.98.

A principios del 2020, los mercados financieros se vieron afectados por la amenaza de guerra entre Irán y Estados Unidos, donde las materias primas como el oro, la plata y el petróleo se vieron afectados y por ello es por lo que se presentó volatilidad en estos activos. Donde este mismo evento llegó a tener un impacto no tan pronunciado en los tipos de cambio.

Los tipos de cambio con la divisa del peso mexicano se empezaron a ver afectados desde el 20 de febrero del 2020 cuando los precios del dólar-peso mexicano, de la libra esterlina-peso mexicano y del euro-peso mexicano empezaron a ir al alza, tuvo efecto la noticia de Emilio Lozoya y la implicación del gabinete presidencial de Enrique Peña Nieto por el caso de Odebrecht, donde este causo una incertidumbre en el mercado además del inicio de los efectos del COVID19. La guerra de precios por los barriles de petróleo empezó el 8 de marzo de 2020, donde Rusia y Arabia Saudita fueron los actores principales ante una búsqueda de un cambio en los precios de esta materia prima, con la búsqueda de modificar la producción del petróleo se hicieron reuniones por parte de la Organización de Países Exportadores de Petróleo, donde la representación de México fue clave para causar movimientos en los precios de cotización de este activo debido a su postura, fue el 20 de abril del 2020 cuando se dio el lunes negro donde los precios de los futuros del petróleo cayeron a puntos negativos, motivo por el cual la divisa mexicana se vio afectada y causo que los tipos de cambio aumentaran. (Véase gráfica 1).

La política monetaria del Banco de México se ha enfocado en reducir las tasas de interés de referencia, esto con el motivo de incentivar la economía mexicana desde que se empezaron a ver los efectos de la pandemia, así también se dedicó a colocar dinero en un intercambio de instrumentos de deuda del gobierno, esto último por la búsqueda de proveer liquidez al sistema financiero mexicano. El Banco de México intervino en gran medida para que los tipos de cambio no siguieran con la tendencia que se estaba marcando a través de subastas cambiarias, esto a través de la Comisión de Cambios integrada por miembros de la Secretaria de Hacienda y Crédito Público como del Banco de México.

Se busca que los agentes económicos crean y tengan confianza en las autoridades monetarias de un país y que las medidas de instrumentos de política monetaria sean de acorde a la situación, es por ello por lo que los bancos centrales y las respectivas autoridades de diferentes economías del mundo tuvieron que efectuar medidas extraordinarias, como lo ocurrido por las autoridades de Estados Unidos y también lo hecho por varios países en la Eurozona. 


\section{Gráfica 1}

Tipo de cambio del USDMXN en 2020

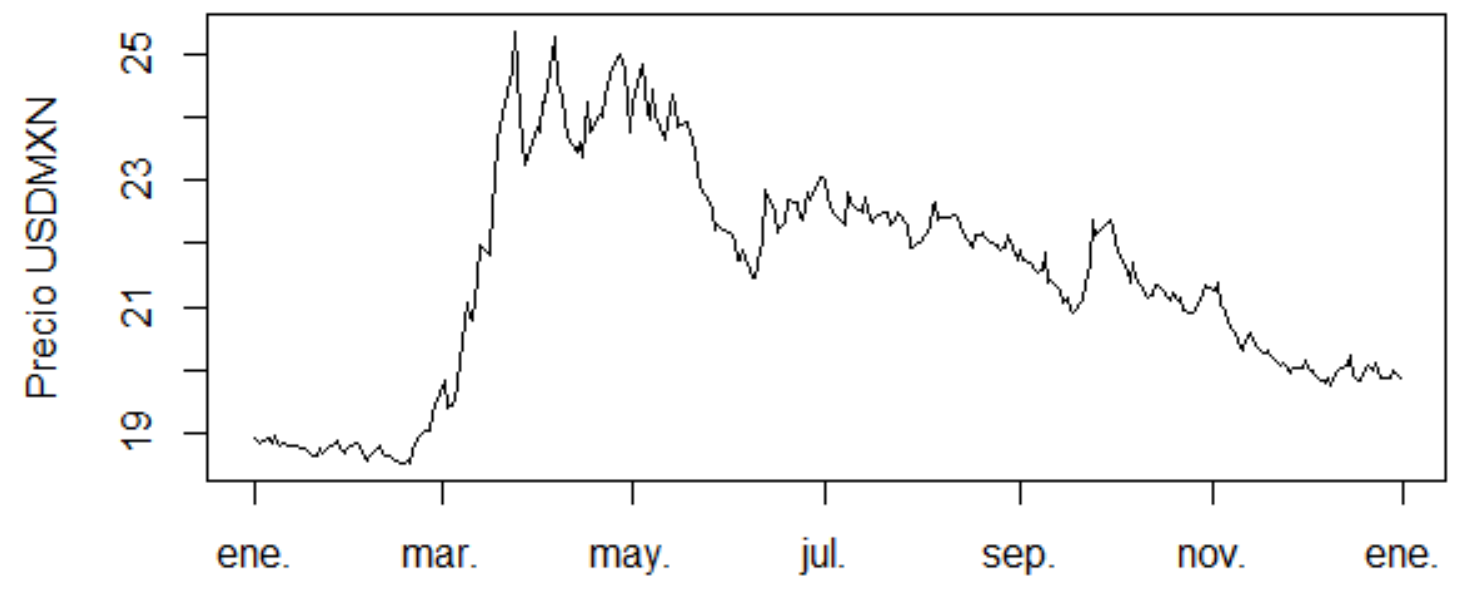

Fecha

Fuente: Elaboración propia con datos de Yahoo Finance (2020).

El tipo de cambio del euro-peso mexicano sigue un comportamiento similar de los tipos de cambio del peso con la libra esterlina y con el dólar. Este se ha vio afectado en 2020 por lo relacionado al COVID19, tanto como las medidas por las dependencias mexicanas para el control de la pandemia como el incremento de casos de contagio; la incertidumbre en política internacional como la incertidumbre de la política nacional tuvieron que ver también con la volatilidad que tuvo el activo, en donde el conflicto entre la Unión Europea y el Brexit tuvieron un impacto significativo reflejado en los precios del tipo de cambio. El EURMXN alcanzó un precio histórico en abril del 2020 cuando este alcanzo los $\$ 27.8$, en los meses de mayo y junio se presentó una apreciación del tipo de cambio del euro-peso mexicano pasando de un precio cercano a $\$ 26.4$ a un precio de $\$ 24.1$, ya en la segunda mitad del 2020, el precio del tipo de cambio tuvo una fluctuación entre \$26.9 y \$23.7 respectivamente. (Véase gráfica 2). 


\section{Gráfica 2}

Tipo de cambio del EURMXN en 2020

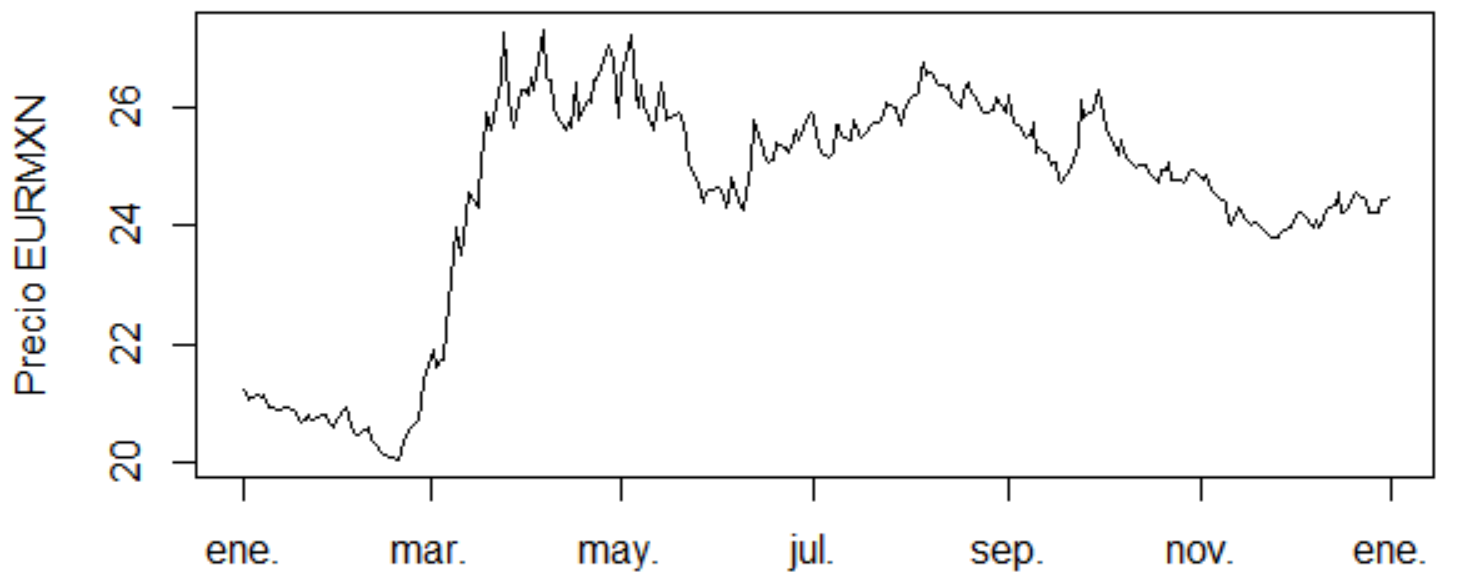

Fecha

Fuente: Elaboración propia con datos de Yahoo Finance (2020).

El tipo de cambio de la libra esterlina-peso mexicano se vio afectado en 2020 principalmente por las cuestiones ocasionadas por el COVID19; así como por las cuestiones por la incertidumbre en política internacional como nacional influenciadas por lo ocurrido con las resoluciones del Brexit como también lo ocurrido por las negociaciones de la OPEP, como las decisiones del gobierno de mexicano para controlar la pandemia. El GBPMXN alcanzó un precio histórico en abril del 2020 cuando sobrepaso los \$31.4, a partir del mes de mayo se observó una apreciación, llegando a un nivel de precio de \$27. En la segunda mitad del 2020, el precio del GBPMXN tuvo una fluctuación entre los\$26 y los \$29. (Véase gráfica 3). 


\section{Gráfica 3}

Tipo de cambio del GBPMXN en 2020

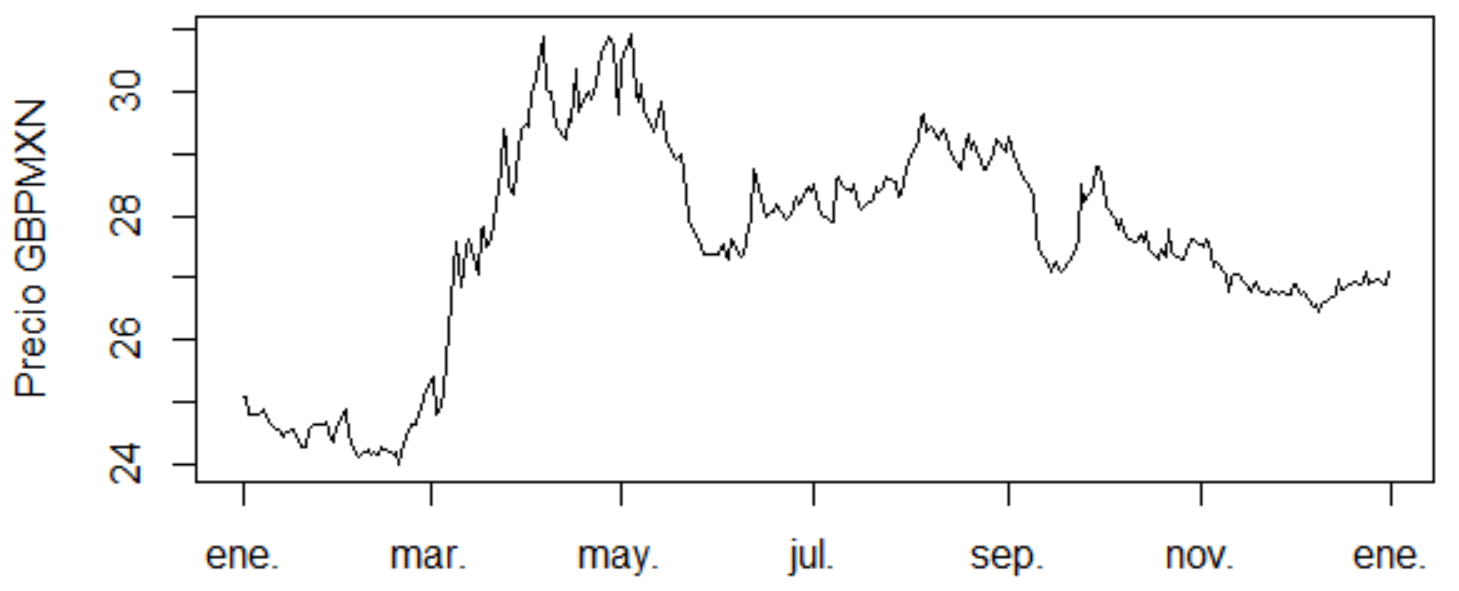

Fecha

Fuente: Elaboración propia con datos de Yahoo Finance (2020).

\section{Análisis técnico e indicadores}

El análisis técnico según Murphy (1999), es aquel análisis que se enfoca en el estudio de los movimientos de los mercados mediante el uso de gráficos, esto con la búsqueda de poder realizar una observación de un posible escenario que se pueda presentar en el precio del activo financiero que se está analizando. Las tres fuentes principales de la información disponible para este tipo de análisis son el precio, el volumen y el interés abierto, este último está enfocado para el mercado de futuros y opciones. Serrano (2014) destaca la importancia del análisis técnico para la visualización del comportamiento de los precios de un activo financiero.

Guadilla (2019) menciona la importancia de los indicadores dentro del análisis técnico, donde estos sirven en gran medida para la toma de decisiones sobre el momento adecuado para abrir una operación.
También recalca de la importancia del volumen, ya que este último se debe apoyar en la tendencia, es decir que el volumen de las operaciones efectuadas debe de ir de acorde con la tendencia, por lo tanto, si hay mayor volumen de operaciones de venta, la tendencia debería ser bajista, en cambio sí hay mayor volumen de operaciones de compra la tendencia debería ser alcista. Es por ello, que se entiende como volumen como la suma de las transacciones que se efectúan en un periodo de tiempo determinado.

Serrano (2019) señala que la tendencia es la trayectoria que toman las diferentes cotizaciones que se puedan dar a lo largo del tiempo, es por ello por lo que esta misma indica la dirección que está tomando la cotización del precio de un activo. Cuando no hay una tendencia clara ya sea bajista o alcista, se entiende que se encuentra en un rango, esto es que hay incertidumbre 
hacia donde se pueda dirigir el precio de cotización. Valdecantos (2016) comenta que, al momento de visualizar los precios en los gráficos, es importante analizar los movimientos que el precio del activo analizado está haciendo, esto mismo en diferentes temporalidades, también la observación del volumen comercializado es otro aspecto para considerar, todo esto para llegar a tomar la mejor decisión al momento de abrir una operación.

En las tendencias de cualquier activo financiero como lo marca Valdecantos (2016) se debiese prestar atención a:

-La tendencia en el largo plazo.

-La tendencia en plazo intermedio.

-La tendencia intra diaria o a corto plazo.

-La tendencia de acuerdo con las manipulaciones de mercado.

Los tipos de cambio con divisa en peso mexicano de acuerdo con lo que comenta Murphy (1999), siguen una tendencia alcista a largo plazo, esto es visible en la gráfica 1, también en el mes de mayo del 2020 se observó un pequeño cambio de tendencia a mediano plazo de forma bajista, esto a causa que hubo una apreciación del tipo de cambio, porque este bajo desde su cotización a un precio histórico arriba de los 25 pesos por dólar hasta llegar a cotizar debajo de los 20 pesos a finales del año 2020.

Guadilla (2019) explica que los indicadores son una base del método para el análisis técnico, ya que, en combinación con los movimientos de los precios, estos proporcionan información relevante para poder efectuar operaciones como toma de decisiones. Estos están compuestos por fórmulas matemáticas y estadísticas aplicadas sobre los diferentes niveles de precios y volúmenes, esto para obtener señales de compra o de venta cuando el precio tiene una interacción con los puntos marcados de sobrecompra o sobreventa. Una ventaja de estos indicadores es que son flexibles y se pueden adecuar de acuerdo con la estrategia que sea más adecuada para el inversionista. Hay dos tipos de indicadores, los que tienden a seguir la tendencia como lo son las medias móviles y los que se mueven entre dos líneas límites como es el caso del stochastic oscillator y del relative strenght index.

\section{Derivados en el Mercado Mexicano de Derivados}

El uso de derivados es aplicable para realizar cobertura sobre tipos de cambio, esto mismo se hace con el fin de evitar pérdidas a través de su uso como coberturas o también con fines especulativos. Dentro de los derivados más usados con divisas se encuentran los contratos de futuros, los contratos forward, las opciones y los swaps. Dentro de los derivados se encuentran diferencias, los contratos de futuros que son contratos estandarizados del cual existe una cámara de compensación en caso de que la contraparte cause incumplimiento; los contratos forward son los derivados hechos a la medida por parte de las partes y por lo mismo, son comercializados vía over the counter, es decir que no hay una cámara de compensación que respalde si llega a presentarse un caso de incumplimiento por alguna de las partes dentro del contrato. En cambio, una opción financiera otorga el derecho mas no la obligación de ejercer esta misma, es por ello por lo que se paga una prima al ejercer esta. Un swap se entiende como un acuerdo de intercambio, en el que las partes se comprometen a intercambiar cada cierto tiempo una serie de flujos monetarios.

En el 2020 por causas de la volatilidad que hubo en los mercados financieros, se realizaron operaciones de 
opciones y contratos de futuros, con el fin de realizar coberturas de la volatilidad de los tipos de cambio, esto fue se presentó con notoriedad entre los meses de marzo a junio (Mercado Mexicano de Derivados, 2020).

Para analizar si una opción es conveniente, es necesario analizar la volatilidad histórica del activo contra la volatilidad implicada de la opción del activo subyacente, en este caso es necesario comparar ambos para analizar si la opción es barata o cara, asimismo ver si es conveniente o no, además de esto es necesario tomar en cuenta otras cuestiones como el valor de la prima. La alta demanda de este tipo de instrumentos financieros tiene raíz por lo acontecido por el COVID19 y los problemas de la resolución en producción petrolera entre la OPEP ${ }^{1}$, el $\mathrm{G}_{20}{ }^{2}$ y Rusia. Los derivados más ocupados entre febrero y marzo del 2020 han sido derivados de contratos de futuros en coberturas cambiarias contra el dólar y swaps, el volumen negociado de swaps concentrado de enero a marzo 2020 ha sido de 2,239,380 operaciones. El volumen negociado en futuros de divisas en marzo fue de 955,577, haciendo un total de volumen negociado contemplando enero, febrero y marzo de 1,519,781. Del total negociado en cuanto al importe concentrado entre enero a marzo ha sido de $\$ 619,317,287,136$ de pesos de lo cual las coberturas de contratos de futuros han sido mayoritarias con un importe de \$395,379,287,136 de pesos. Por lo tanto, han sido el producto derivado más usado, por encima de las opciones y los swaps.

Para los meses entre mayo a agosto del 2020, debido a la apreciación del peso mexicano en contra de las otras divisas como el dólar, bajaron el nivel de operaciones efectuadas, donde si hubo una gran comercialización de productos derivados enfocados a índices bursátiles. El que haya bajado el nivel de operaciones de derivados con divisas no significó que bajase su volumen ni el importe comercializado, ya que el volumen y los importes por productos derivados en divisas son los que tienen más peso dentro de los productos comercializados (Mercado Mexicano de Derivados, 2020).

A principios del año 2020, los futuros del peso mexicano cotizaban arriba de $\$ 0.05$ donde la cotización de este activo se vio afectada en la cúspide de la pandemia y cuarentena en el país, donde mostro una nueva alza en su cotización a partir del mes de junio. (Véase grafica 4).

\footnotetext{
${ }^{1}$ Organización de Países Exportadores de Petróleo, lo integran las economías: Angola, Arabia Saudita, Argelia, Emiratos Árabes Unidos, Gabón, Guinea Ecuatorial, Irán, Irak, Kuwait, Libia, Nigeria, República del Congo, Venezuela.

${ }^{2}$ Grupo de los 20, las economías que lo integran son: Alemania, Arabia Saudita, Argentina, Australia, Brasil, Canadá, China, Corea del Sur, Estados Unidos, Francia, India, Indonesia, Italia, Japón, México, Reino Unido, Rusia, Sudáfrica, Turquía y la Unión Europea.
} 


\section{Gráfica 4}

Futuros del peso mexicano 6M en el 2020

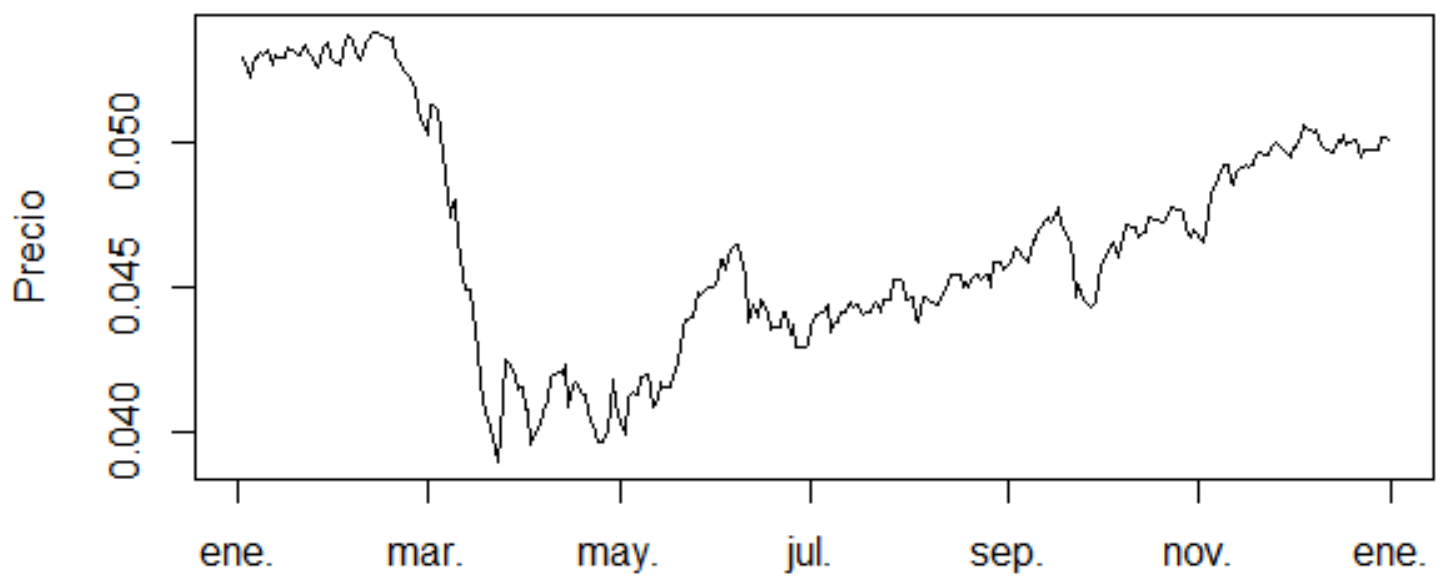

Fecha

Fuente: Elaboración propia con datos de Yahoo Finance (2020).

\section{Índice de fuerza relativa}

El Relative Strenght Index (RSI) o por su nombre en español como índice de fuerza relativa es un indicador de impulso que se utiliza en el análisis técnico, este mide la proporción de los cambios de precio recientes para evaluar las condiciones de sobreventa o de sobrecompra en el precio de un activo financiero (Wilder,1978).

Un activo financiero se considera en sobrecompra cuando el RSI está por encima del $70 \%$ y se considera en sobreventa cuando está por debajo del 30\%. Este mismo se muestra como un oscilador debido a que este gráfico se mueve entre dos extremos y su lectura puede darse entre 0 y 100.

La fórmula para su cálculo es la siguiente:
Índice de fuerza relativa = $100-[100 /(1+\mathrm{RS})]$

Donde:

RS = (Promedio de ganancias en el periodo del cálculo) / (Promedio de perdidas en el periodo de cálculo)

Periodo de cálculo $=$ Precios de cierre de las últimas 14 sesiones.

Este método sirve para llegar a tomar decisiones de compra o de venta de un activo si el activo de estudio llega a los puntos límites de sobre compra o de sobre venta. Cuando se alcanza nivel de sobrecompra, es una fuerte señal de venta del activo; en cambio cuando se alcanza niveles de sobreventa, es una fuerte señal de compra del activo. 


\section{Oscilador estocástico}

Un oscilador estocástico o Stochastic Oschillator, de acuerdo con Lane (1984) es un indicador de impulso, este compara un precio de cierre de un valor con el rango de sus precios durante un cierto período de tiempo estudiado.

Este método es utilizado para generar señales de sobrecompra y sobreventa de un activo financiero, utilizando un rango de valores entre 0 y 100 . $\% \mathrm{~K}$ se denomina indicador estocástico lento. El indicador estocástico que es rápido es \% D Se entiende si tanto como \%k y \%D son superiores a 75 se considera que hay sobrecompra, y las lecturas que son inferiores a 25 se considera que hay sobreventa.

Para el oscilador estocástico rápido la fórmula es la siguiente:

$\% \mathrm{~K}$ rápido $=$ (Cierre actual-Mínimo más bajo) $/$ (Máximo más alto-Mínimo más abajo) * 10

$\% \mathrm{D}$ rápido $=$ media móvil simple que se aplica sobre él \%K rápido.

Para el caso del oscilador estocástico lento la fórmula es la siguiente:

$\% \mathrm{~K}$ lento $=\% \mathrm{~K}$ rápido suavizado por medio de media móvil simple a 3 periodos.

$\% \mathrm{D}$ lento = media móvil a 3 periodos del \%K lento

Así como en el índice de fuerza relativa, los osciladores estocásticos aplicados al trading y a la inversión en activos financieros, sirven para poder efectuar entradas óptimas tanto de compra como de venta, una vez que se tocan los niveles de sobrecompra y sobreventa respectivamente. El \%D corresponde a una media móvil simple, que se entiende como una media aritmética aplicada a los 3 datos anteriores, la cual sirve para visualizar la tendencia del activo. En el oscilador estocástico rápido de la presente investigación se utilizan los precios diarios de los activos, tanto en su precio de cierre, como su precio más alto alcanzado en el día como también el precio más bajo del día, como se muestra en \%K. Para el caso del oscilador estocástico lento, se utiliza una suavización del \%K a través del uso de una media móvil a 3 periodos. \%D sirve para visualizar la tendencia que está siguiendo el activo, asimismo este sirve como guía para la toma decisión de realizar una operación ya sea de compra o venta una vez alcanzados los niveles límites de sobrecompra y sobreventa, donde como apoyo también se pueden usar los \%K y la línea de señal.

\section{Resultados}

Para el índice de fuerza relativa se usaron fechas correspondientes del 1 de enero del 2020 al 31 de diciembre de 2020. El motivo del uso de estas fechas fue para analizar los movimientos que hicieron estos activos financieros durante el 2020.

Como lo marca la teoría del modelo, un inversionista puede tomar decisiones de comprar el activo estudiado una vez que toque el punto de sobreventa, asimismo puede tomar una decisión de venta una vez que se muestren señales de sobrecompra. El dólar-peso mexicano reflejó durante el 2020 que se presentaron ambas señales. Desde que hubo un aumento de casos de COVID19 como también lo acontecido por los eventos de la OPEP, provocó que el USDMXN se fuese al alza, hasta llegar a un precio histórico como se observa en la gráfica 1, la aplicación del modelo como lo muestra la figura 1, es que cuando el precio del activo llegó a estos niveles históricos, se presentaron niveles de sobrecompra, por lo que fue una clara señal de venta. La primera señal de sobreventa se presentó una señal de compra y esto se dio en el mes de junio, una vez que el tipo de cambio alcanzó un precio por debajo de los $\$ 21.5$, con esta señal 
de sobreventa se pudo haber tomado una operación de compra, ya que a principios de julio del 2020 el tipo de cambio alcanzó un precio arriba de los \$23.2, por lo que si se hubiese hecho una operación de compra se hubiera sacado rendimiento. La segunda señal por sobreventa se presentó en septiembre del 2020, esto fue cuando el tipo de cambio llego a un precio cercano de \$20.8, por lo cual como lo enmarca el modelo pudo haber sido una buena señal de compra, debido a que el precio luego alcanzó un nivel superior de los \$22.6. En la tercera señal de sobreventa ocurrió entre noviembre y diciembre del 2020, como se muestra en la figura 1, la línea de señal toca varias veces el nivel de sobreventa, esto fue motivo porque el precio venia disminuyendo, donde en noviembre se encontraba arriba de los \$21.9 y en diciembre llegó a un nivel de precio de \$19.7, por lo que el tipo de cambio se mantuvo en estos niveles de precio e igualmente mostrando niveles de sobreventa, por lo que se dio una subida del precio hasta finales de abril cuando se llegó a un precio de \$20.6. (Véase figura 1).

\section{Figura 1}

Índice de fuerza relativa USDMXN

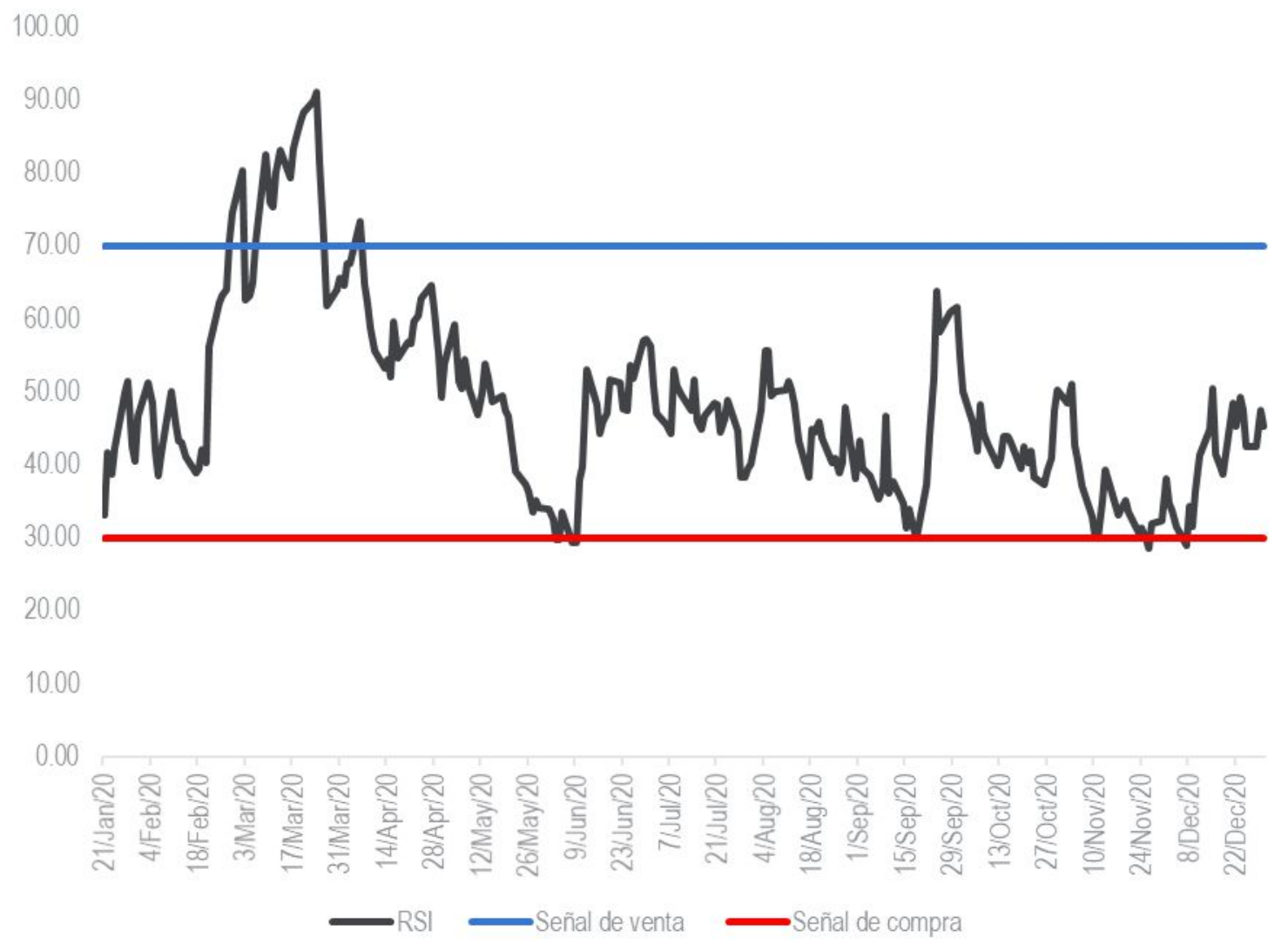

Fuente: Elaboración propia con datos de Yahoo Finance (2020). 
El tipo de cambio del euro con el peso mexicano se vio afectado por varias circunstancias además de lo acontecido por el COVID19, en la figura 2, se observa que hubo dos veces en los que se presentaron niveles de sobrecompra, el primero se dio en el mes de abril donde fue el auge e incremento de contagios como donde también hubo incertidumbre en la economía por el cierre industrial. En el nivel de sobrecompra que se presentó en abril cuando el tipo de cambio del euro superó el precio de \$27.8, pudo haber sido una buena oportunidad para haber efectuado operaciones de venta. En cambio, la segunda vez que tocaron niveles de sobreventa fue a finales de julio y principios de agosto, donde el precio del EURMXN fue cercano a \$26.9, en donde también fue una buena oportunidad para efectuar una operación de venta. Con las señales de sobrecompra se pudo observar que también se avecinaba una apreciación del tipo de cambio, lo cual ocurrió. La primera vez que se tocó el nivel de sobreventa fue a inicios de la pandemia de COVID19 en el país en febrero del 2020, en el cual cotizaba a un precio de \$20 que después de unas semanas el EURMXN alcanzó un precio cercano de $\$ 27.8$, la cual pudo haber sido una buena oportunidad de compra. La segunda vez que se llegó al nivel de sobreventa fue en septiembre, cuando el precio del activo llego a \$24.7, en la cual también hubiese sido una buena oportunidad de compra, dado que días después el precio alcanzo los \$26.4. La última señal de sobreventa se dio entre noviembre y diciembre, esto a causa de que no hubo mucha fluctuación del precio en estos meses, pero igualmente hubo una señal de compra dado que el precio paso de \$23.7 a superar el precio de \$25 en cuestión de días. (Véase figura 2). 
Figura 2

Índice de fuerza relativa EURMXN

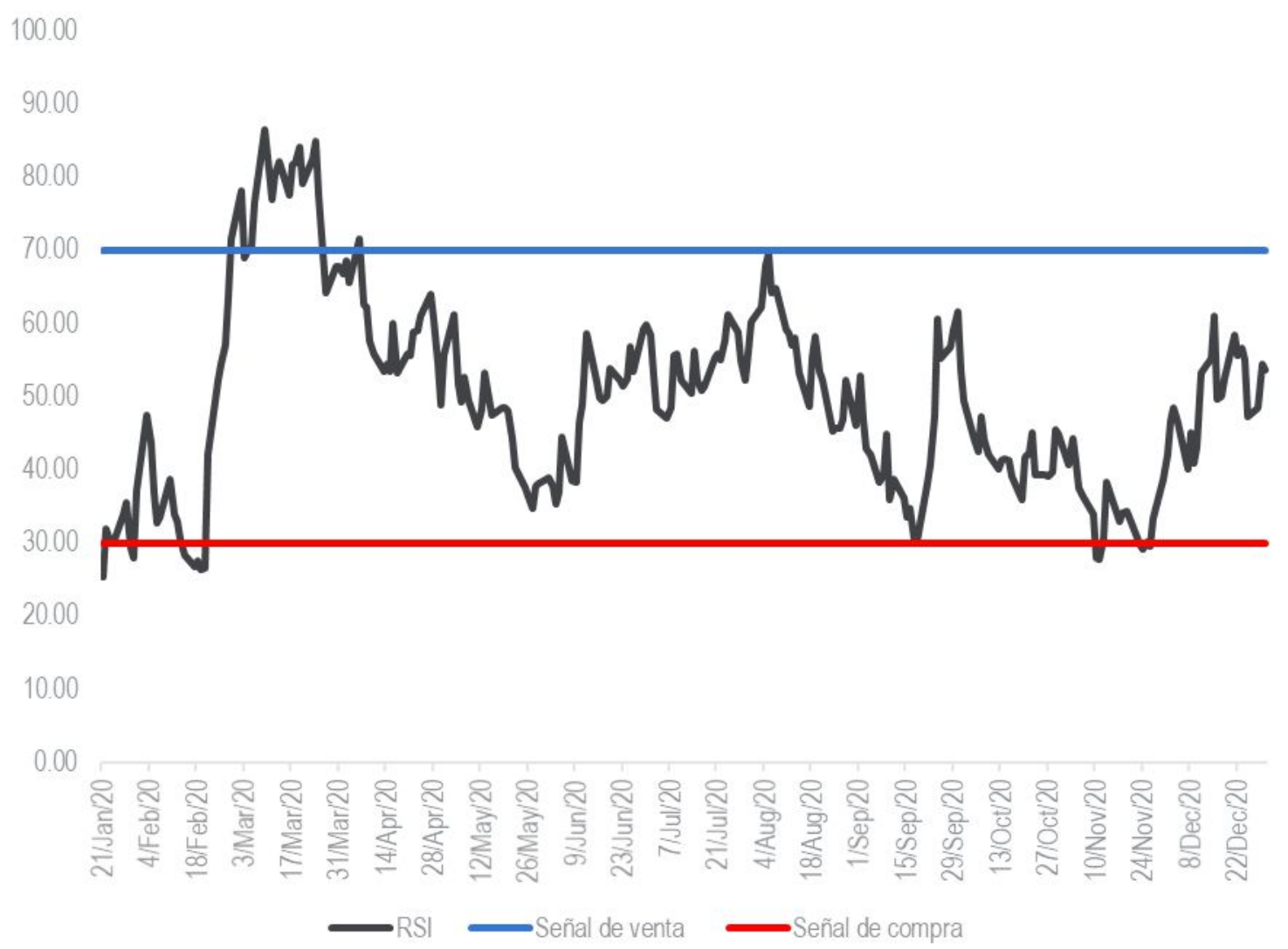

Fuente: Elaboración propia con datos de Yahoo Finance (2020).

El tipo de cambio de la libra esterlina tuvo un desarrollo algo similar al del EURMXN, pero este activo además de las cuestiones del COVID19 y los acontecimientos mencionados, también la resolución del Brexit, tuvieron que ver en los movimientos que hizo el activo. La primera señal de sobrecompra se dio en los meses de marzo y abril, en donde el tipo de cambio alcanzo un precio histórico, en donde el tipo de cambio fluctuó entre los precios de \$29-\$31.3 en este lapso, ya en el mes de mayo hubo una apreciación del tipo de cambio, mostrando una señal de venta del activo, ya que desde su precio máximo alcanzado paso a cotizar a un precio en junio de \$27. La segunda vez que se presentó sobrecompra fue en el mes de agosto cuando el precio del GBPMXN superó los \$29.8, luego de alcanzar este nivel, el precio del activo cayo, por lo cual pudo haber sido una oportunidad de venta. La primera vez que se presentó sobreventa del activo fue en desde enero y 
febrero del 2020, cuando recién comenzaba la pandemia en el país como aumentaban los contagios en Europa, donde se encontraba a un precio inferior de $\$ 24$, donde pudo haber sido una oportunidad de compra, debido a que en unas semanas el precio alcanzó a superar los \$31.4, haciendo un máximo histórico. La segunda vez que se presentó sobreventa fue a finales del mes de mayo y principios de junio, donde el precio del activo llegó a \$27, donde también pudo haber sido una oportunidad de compra, debido a que semanas después, el precio alcanzó los \$29.8. La última señal de sobreventa se dio en septiembre, cuando el precio volvió a \$27, donde también se presentó una oportunidad de compra, debido a que días después el precio alcanzó los \$29. (Véase figura 3).

\section{Figura 3}

Índice de fuerza relativa GBPMXN

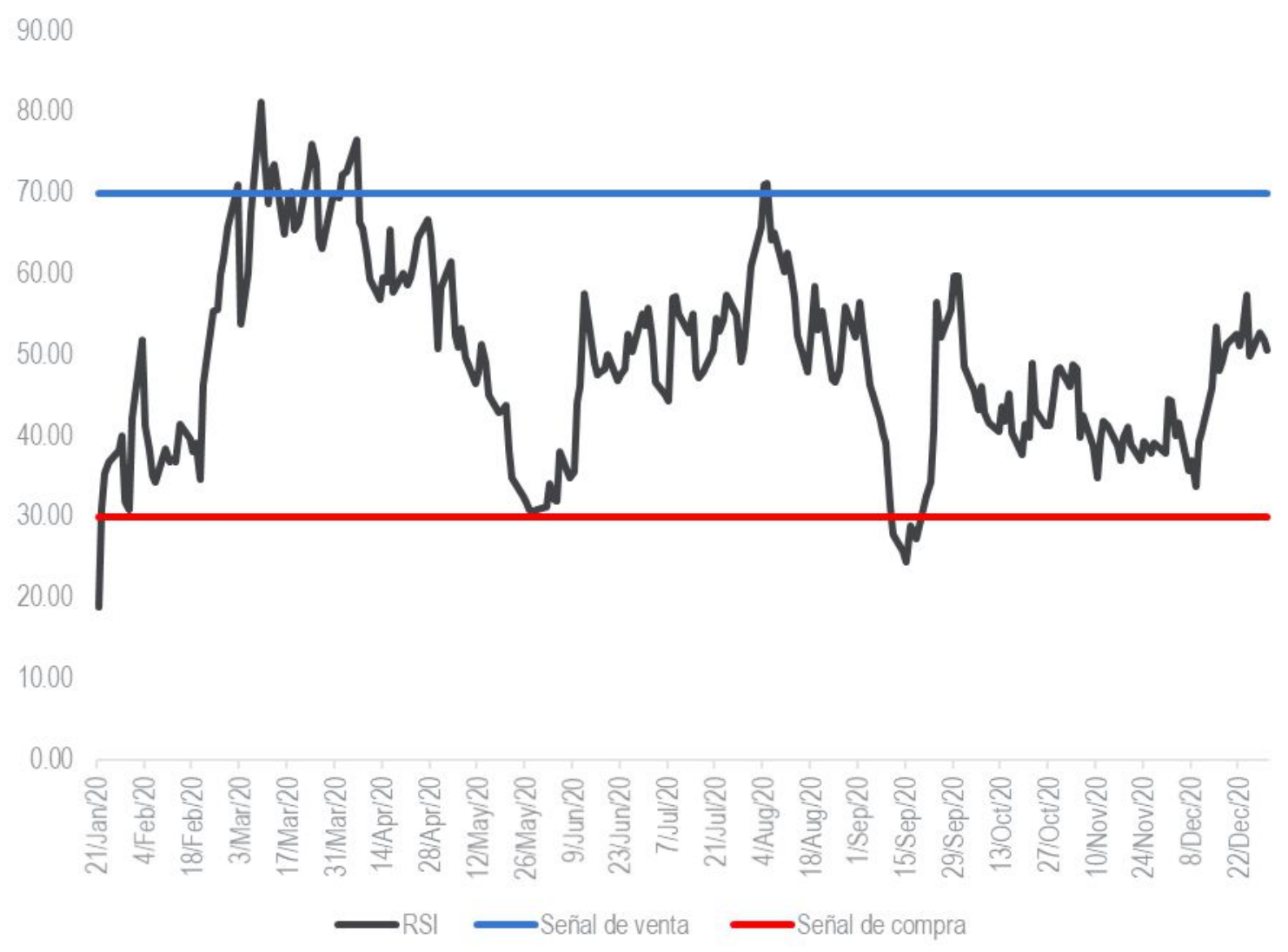

Fuente: Elaboración propia con datos de Yahoo Finance (2020). 
Tanto, en el oscilador estocástico rápido como en el oscilador estocástico lento se usaron datos de los precios de los activos del 2020, correspondientes del 1 de enero al 31 de diciembre, en los cuales se usaron los precios de cierre del día, el precio más alto que alcanzo el activo en el día como el precio más bajo que alcanzo el activo durante el día. Ambos osciladores ocupan una media móvil simple, la cual una vez que llega a los niveles límites, se pueden tomar decisiones de compra o venta. Para el caso de los osciladores estocásticos rápidos, la línea amarilla corresponde a \%K, mientras que la línea negra corresponde a \%D que es la media móvil simple. Para el caso de los osciladores estocásticos lentos, la línea amarilla corresponde la línea de señal y la línea negra corresponde a \%D que es la media móvil simple.

Las interpretaciones realizadas para los osciladores estocásticos son aplicadas tanto para el oscilador estocástico rápido como para el lento, esto debido a que los modelos comparten el resultado de $\% \mathrm{D}$ que es la media móvil simple, la cual se usa para llegar a tomar decisiones una vez que se llega a los límites de sobrecompra o sobreventa, pero a pesar de que existan similitudes en las interpretaciones, también se marcan unas diferencias. La diferencia principal es sobre \% $\mathrm{K}$ la línea de señal, donde se aplica el primero para el oscilador estocástico rápido y el segundo para el oscilador estocástico lento.
En la figura 4 se encuentran los resultados del oscilador estocástico rápido aplicado al dólar-peso mexicano. Los niveles de sobrecompra fueron tocados varias veces, asimismo los niveles de sobreventa. En la primera parte de la figura 4 se observa cómo se llegó a niveles de sobrecompra cuando el precio del USDMXN iba en una subida pronunciada desde febrero del 2020 como se muestra en la gráfica 1 , asimismo cuando el precio del tipo de cambio alcanzó su precio máximo de marzo, este mostro una apreciación debido a que bajo el precio del USDMXN, hasta llegar a un precio de \$22.8, una vez que llego a ese precio, paso de nuevo a subir y a realizar su nuevo máximo histórico, una vez alcanzado el máximo, también se presente sobrecompra, por lo que fue una oportunidad de venta. En los meses de julio y septiembre, igualmente se alcanzaron niveles de sobrecompra, por lo que pudieron ser también buenas oportunidades de venta. En el caso de los niveles de sobreventa, los primeros se dieron en los meses de enero y de febrero, antes de que comenzara el efecto de la pandemia en el país, por lo que una oportunidad de compra era favorable. En abril y junio, se presentaron también niveles de sobreventa, esto se debió a que el USMXN iba a la baja debido a la apreciación del peso con respecto al dólar. Asimismo, en julio, septiembre, octubre y noviembre se presentaron niveles de sobreventa, con lo cual se pudieron haber efectuado operaciones de compra. (Véase figura 4). 


\section{Figura 4}

\section{Oscilador estocástico rápido USDMXN}

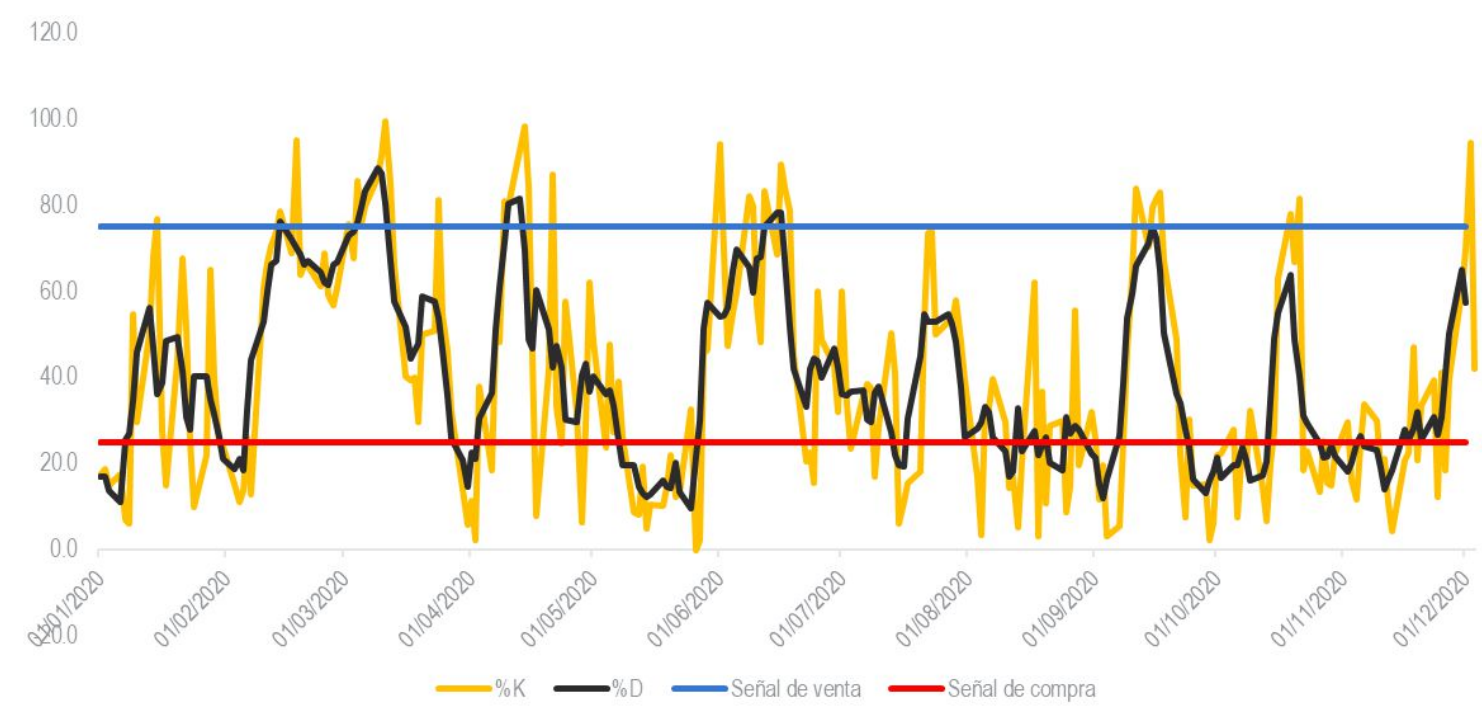

Fuente: Elaboración propia con datos de Yahoo Finance (2020).

Las señales presentes para el oscilador estocástico lento del dólar-peso mexicano son muy parecidas a las planteadas en la interpretación del oscilador estocástico rápido. El uso de la línea de señal del oscilador estocástico lento sirve para tomar las señales presentadas de forma más precisa, esto debido a que el resultado suavizado del \%K del oscilador estocástico rápido.

En el mes de junio se presentó una sobreventa del activo, como muestra la línea de señal, es que apenas toca la línea límite de sobreventa, por lo que se pudo haber efectuado una orden de compra, pero en realidad el precio del USDMXN no subió mucho. Las señales presentadas por la línea de señal de agosto y principios de septiembre marcan que hubo sobreventa, pero se pudo haber tomado una postura de compra a mediados del mes de septiembre ya que empezó a presentarse una subida de precio y hubiera sido una entrada óptima en vez de haberla realizado en agosto. (Véase figura 5). 


\section{Figura 5}

\section{Oscilador estocástico lento USDMXN}

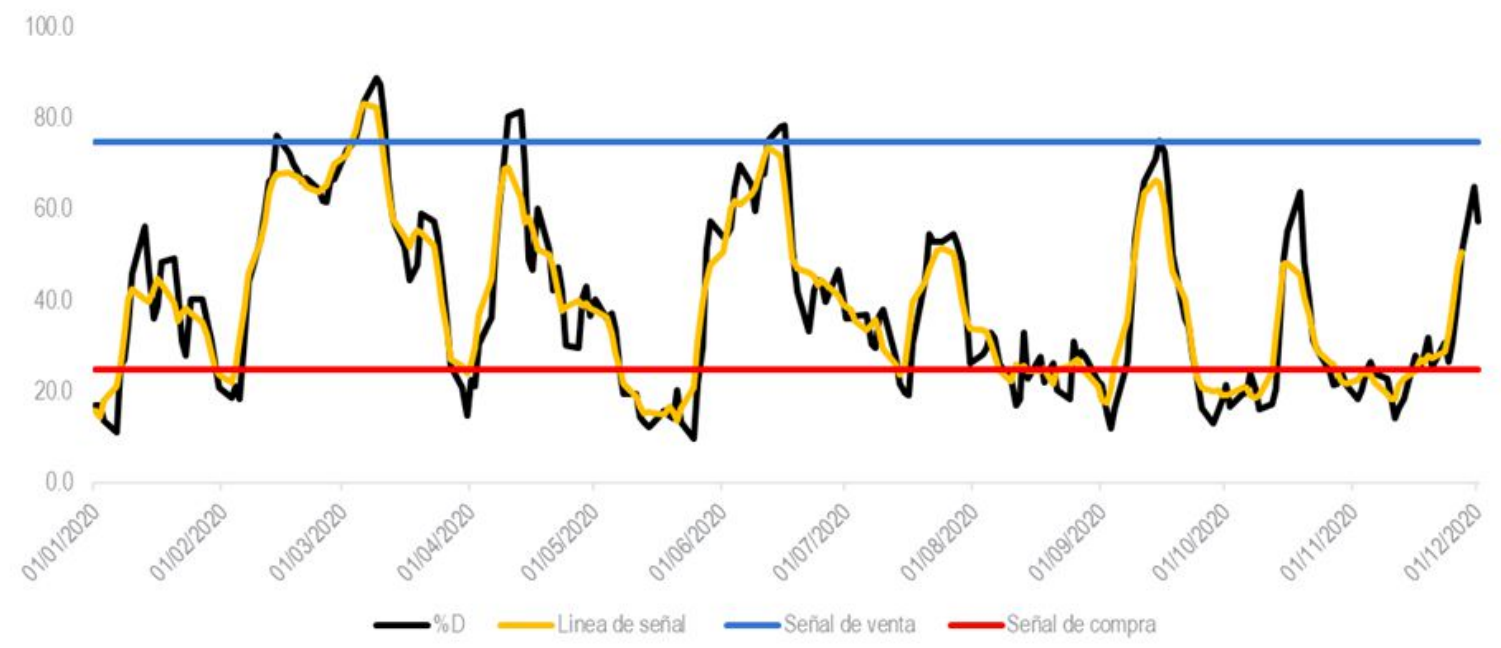

Fuente: Elaboración propia con datos de Yahoo Finance (2020).

En la figura 6 se encuentran los resultados del oscilador estocástico rápido aplicado al euro-peso mexicano. La primera señal de sobrecompra se presentó en el mes de marzo en donde el precio había ido aumentado desde febrero, por lo que pudo ser una oportunidad de venta. La segunda señal de sobrecompra se dio en abril una vez que el precio alcanzó un nuevo máximo histórico arriba de \$27.8, por lo que se presentó una oportunidad de venta. La tercera señal de sobrecompra se presentó en el mes de mayo, en donde si se hubiera ejecutado se pudo haber aprovechado la bajada de precio que sufrió el EURMXN desde \$27.3 hasta \$24.1 en el mes de mayo. En junio se presentó un nivel de sobrecompra, pero del cual, si se hubiese efectuado una venta, se hubiera aprovechado solo un poco de la bajada de precio que se presentó. En cambio, en agosto igualmente hubo señal de sobrecompra y se pudo efectuar una venta, el precio del EURMXN llego a cotizar en \$26.8 en agosto. A finales de septiembre y principios de octubre se presentó la última señal de sobrecompra, donde igualmente se pudo efectuar una operación de venta.

En el caso de los niveles de sobreventa, los primeros se dieron en los meses de enero y de febrero, antes de que comenzara el efecto de la pandemia en el país pero que ya estaba presente en Europa, por lo que una oportunidad de compra fue favorable, ya que después el EURMXN alcanzó precios históricos. En abril y junio, se presentaron también niveles de sobreventa, en donde se pudieron haber efectuado operaciones de compra, ambas ocurrieron porque el peso mexicano se había apreciado en contra del euro en las dos ocasiones. Asimismo, en septiembre hubo también señal de sobreventa llegando a un precio de \$24.7 y luego subiendo a un precio de \$26.4 en cuestión de días. Se presentaron niveles de sobreventa en octubre $\mathrm{y}$ noviembre, donde se pudieron efectuar operaciones de compra, pero el precio no subió mucho. (Véase figura $6)$. 


\section{Figura 6}

\section{Oscilador estocástico rápido EURMXN}

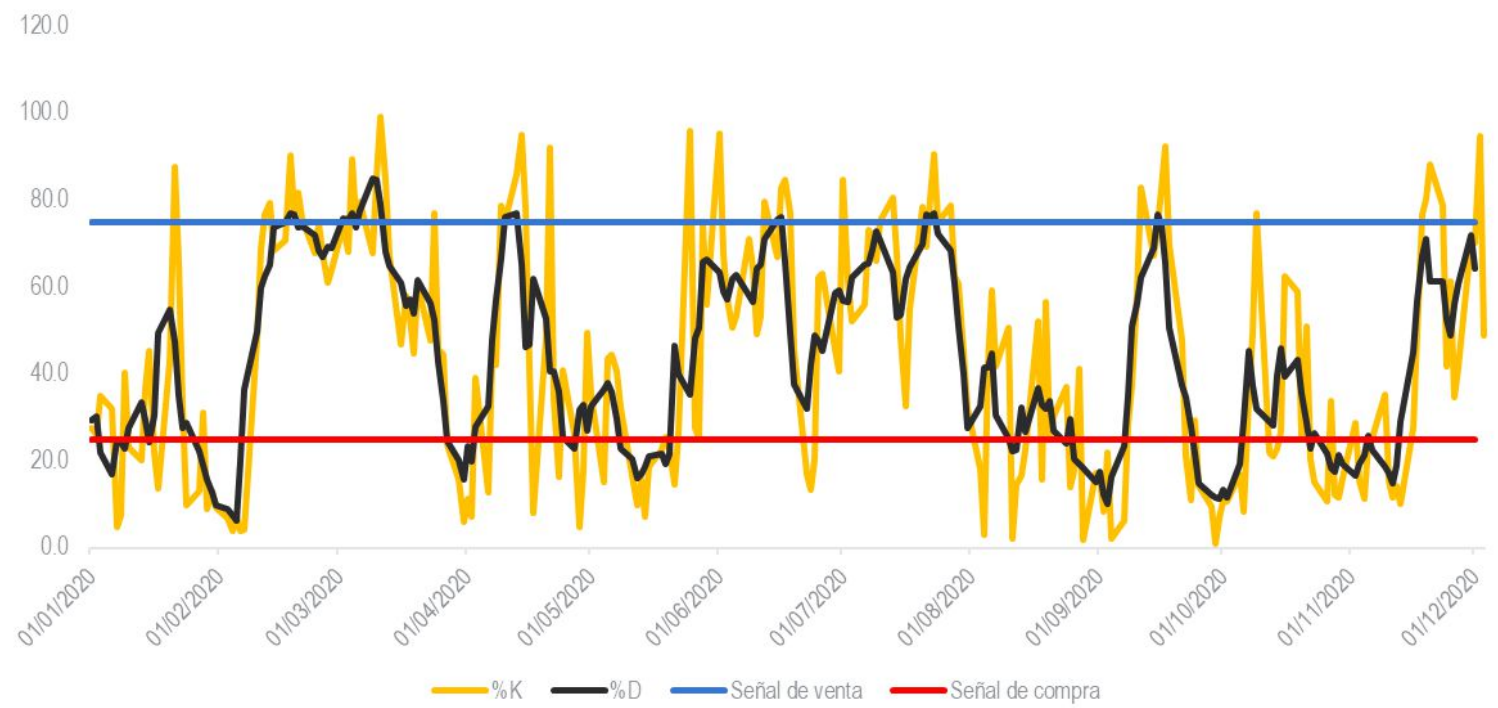

Fuente: Elaboración propia con datos de Yahoo Finance (2020).

Las señales presentes para el oscilador estocástico lento del euro-peso mexicano son muy parecidas a las planteadas en la interpretación del oscilador estocástico rápido.

En el mes de agosto se presentó una señal de sobreventa marcada por la línea de \%D que es el de la media móvil simple, pero no fue tocada por la línea de señal, pero el precio del activo siguió cayendo, haciendo más clara la señal de sobreventa, donde se pudo haber efectuado una operación de compra en septiembre como se muestra en la figura 7. 


\section{Figura 7}

\section{Oscilador estocástico lento EURMXN}

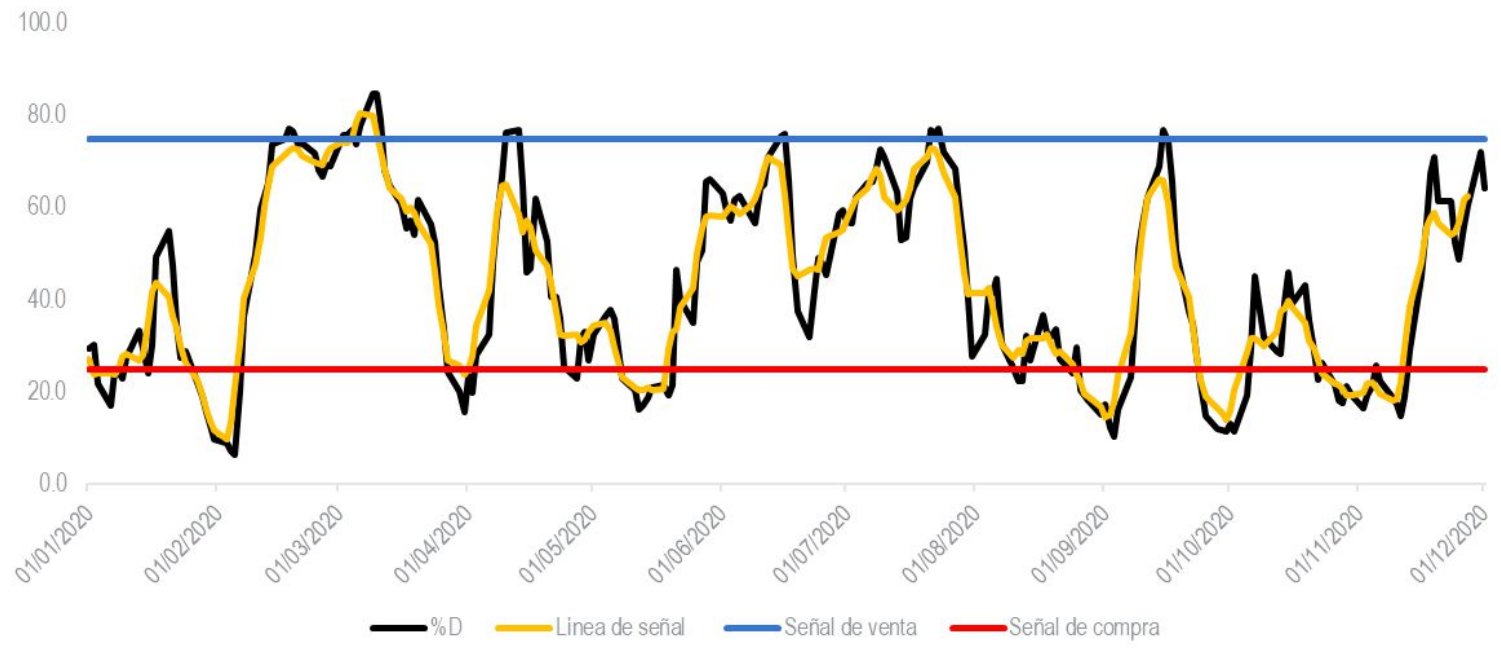

Fuente: Elaboración propia con datos de Yahoo Finance (2020).

En la figura 8 se encuentran los resultados del oscilador estocástico rápido aplicado a la libra esterlinapeso mexicano. La primera vez que se toca el nivel de sobrecompra donde también hubo una oportunidad de venta, ocurrió cuando el tipo de cambio de la libra esterlina con respecto al peso mexicano hizo su precio máximo en abril, esto porque venía de una tendencia alcista pronunciada desde febrero del 2020 como se muestra en la gráfica 3 , una vez que llego a ese precio histórico, el tipo de cambio paso a apreciarse y luego de nuevo a subir, asimismo provoco que se presentase un nivel de sobrecompra en mayo por lo que se presentó una oportunidad de venta. En junio se alcanzó nivel de sobrecompra, pero en este caso en particular, si se hubiera ejecutado una operación de venta se debió de haber tomado con cuidado, debido a que el GBPMXN pasó de \$28.7 a \$27.7 en cuestión de días y luego después de haber bajado siguió subiendo el precio hasta alcanzar los \$29.8 en agosto, donde se presentó sobrecompra y se pudo haber realizado una venta. La última señal de sobrecompra se dio en septiembre, una vez que el precio alcanzó los \$29, pudo ser una oportunidad de venta. En el caso de los niveles de sobreventa, los primeros se dieron en los meses de enero y de febrero, antes de que comenzara el efecto de la pandemia en el país, por lo que una oportunidad de compra era óptima. A finales de mayo, se presentaron también niveles de sobreventa, esto se debió a que el GBPMXN iba a la baja debido a la apreciación del peso con respecto a la libra esterlina, donde llegó a un precio de \$27.2. Asimismo, en septiembre, se presentó otro nivel de sobreventa, debido a la bajada del precio, del cual llego a \$27, donde fue una oportunidad para una operación de compra, ya que días después el precio del GBPMXN subió. En el caso de los niveles de sobreventa presentados en octubre y en noviembre, se 
pudieron haber efectuado operaciones de compra, pero el precio no subió mucho en estas fechas. (Véase figura 8).

\section{Figura 8}

\section{Oscilador estocástico rápido GBPMXN}

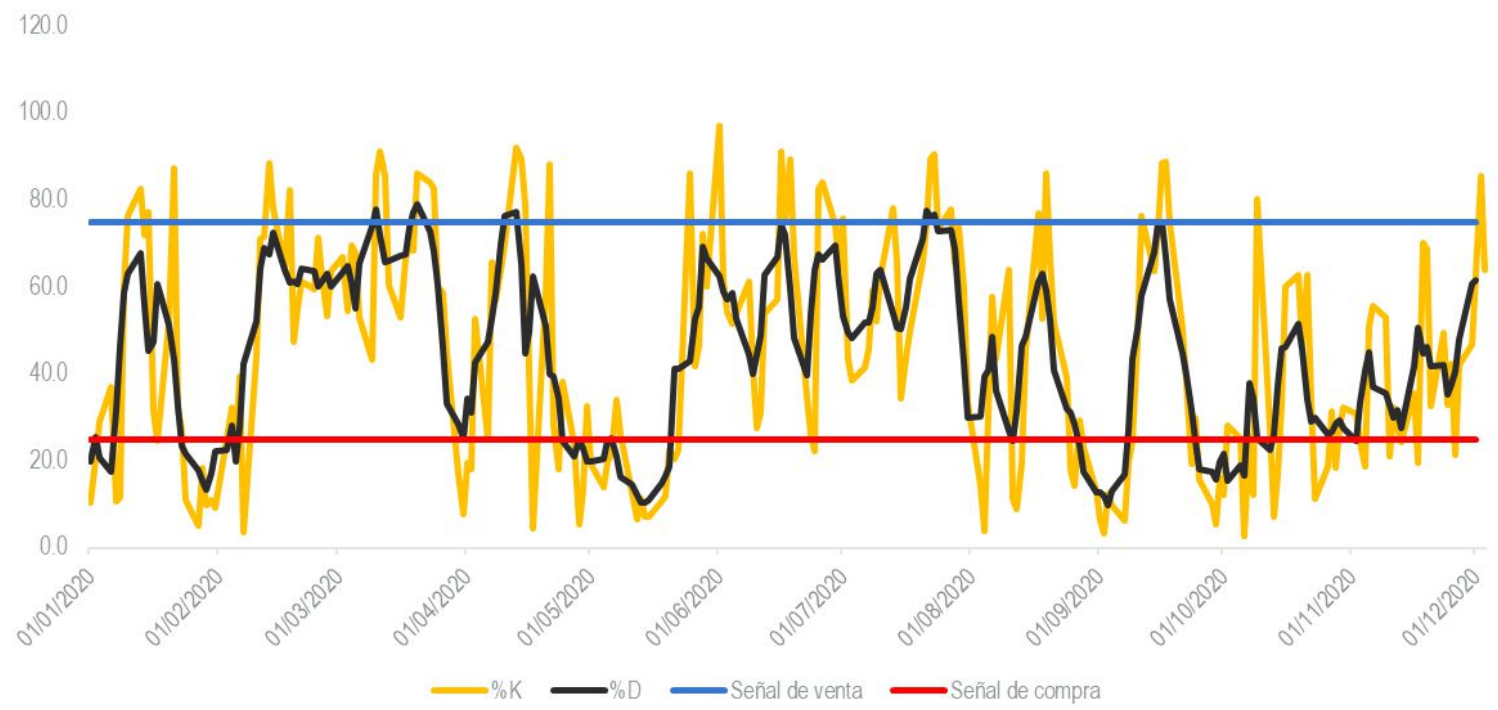

Fuente: Elaboración propia con datos de Yahoo Finance (2020).

Las señales presentes para el oscilador estocástico lento de la libra esterlina-peso mexicano son muy similares a las planteadas en la interpretación del oscilador estocástico rápido. En el mes de mayo se presentó una señal de sobreventa, pero el precio siguió cayendo por lo cual el nivel de sobreventa se mantuvo por unos días más, como se observa en la figura 9; esto se dio a causa de que el tipo de cambio se había estado apreciando desde que este hiciera su máximo histórico. Asimismo, las señales de sobreventa a finales de octubre y en noviembre son más claras con la línea de \%D que pertenece a la media móvil simple en comparación de la línea de señal, por lo que, a pesar de haber dado una señal de compra por la sobreventa, un inversionista pudo haber tomado la decisión de tomarla o no. 


\section{Figura 9}

Oscilador estocástico lento GBPMXN

\section{Oscilador estocástico lento GBPMXN}

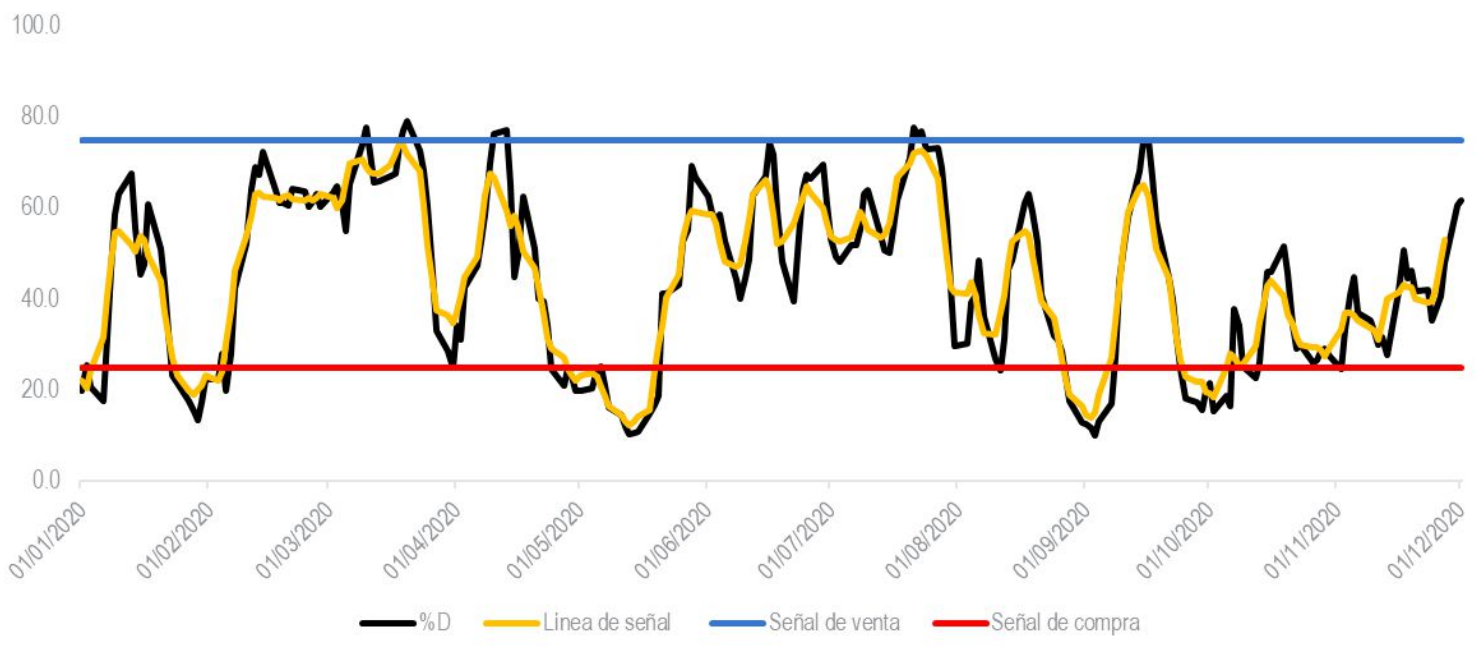

Fuente: Elaboración propia con datos de Yahoo Finance (2020).

\section{Discusión}

Hernández y Castro (2020) explican que en cualquier inversión está presente el riesgo, pero que en activos financieros como las divisas también está presente la volatilidad, es por ello por lo que tanto herramientas como indicadores pueden ser aplicados para buscar entradas óptimas en operaciones de trading.

Gumparthi (2017) menciona que el uso del índice de fuerza relativa puede mostrar señales óptimas, en su investigación utiliza el modelo para analizar 20 acciones que cotizan en el NSE que es la bolsa de valores de la India, con los resultados obtenidos del estudio se encontró que el RSI es una de las herramientas de análisis técnico más eficaces disponibles y esta puede utilizarse para la creación de un portafolio de inversión, esto por las señales que se dieron de compra y venta. Es por ello por lo que Serrano (2014) recomienda el uso de este tipo de herramientas para apoyarse en la toma de decisiones al ejecutar una operación siempre y cuando se realice siguiendo la tendencia del activo.

Ni, Liao y Huang (2015) aplican la herramienta de análisis técnico del oscilador estocástico para el análisis de las acciones con presentación de momentum, este mide la velocidad de los cambios en los precios del mercado de un activo financiero estudiado durante un período de tiempo determinado y este mismo sirve para visualizar tendencias, en el trabajo estudiado por los autores se analizan acciones del índice SSE $50^{1}$ chino. Con el uso

${ }^{1}$ Es el índice bursátil de la Bolsa de Valores de Shanghai, este índice representa a las 50 principales empresas por capitalización. 
de los osciladores estocásticos en presentación de momentum se analizaron los rendimientos de inversionistas que realizaron operaciones de acciones cuando se mostraba sobrecompra, con lo que demuestran que con el uso de osciladores estocásticos se pueden realizar entradas óptimas.

Taran (2011) argumenta que el uso del indicador de fuerza relativa muestra oportunidades de inversión que pudiese tomar un inversionista, además argumenta que tomando las entradas cuando se dan las señales ya sea de compra o de venta, se pueden tener buenos resultados.

La crítica a estos modelos es que solo miden entradas por las señales que se presentan ya sea en las líneas de límites de sobrecompra o sobreventa, más en cambio, no se da una señal como tal de salida, es decir, estos modelos sirven para tomar decisiones de cuando entrar en una operación ya sea de compra o venta, pero no sirven para saber cuándo salir de la misma. Si bien el enfoque del uso de estas herramientas es para poder tomar decisiones de inversión, también puede servir para visualizar que tendencia y movimientos podría hacer el activo de estudio, pero estos movimientos y la tendencia pudiesen durar muy poco tiempo, por lo que se debiese ser atento al momento de hacer uso de estas herramientas; también la toma de decisiones a través del apoyo de estas herramientas conlleva un riesgo que el inversionista debe estar dispuesto a asumir. Asimismo, Shleifer (2000) argumenta que los mercados no son del todo eficientes por la aplicación de las finanzas conductuales, pero destaca que, con el uso de herramientas, se pueden obtener buenos resultados al momento de operar activos financieros.

\section{Conclusión}

El uso de herramientas como el índice de fuerza relativa como también los osciladores estocásticos, permiten a la persona interesada el poder tomar decisiones de compra o venta siempre y cuando en los modelos se toquen los puntos límites de sobrecompra y sobreventa según sea el caso; por lo que las hacen herramientas competentes para poder realizar operaciones que puedan resultar en positivas. Ante movimientos de volatilidad, estas herramientas pueden servir para toma de decisiones cuando se desea efectuar una operación, esto debido que ante un aumento prolongado del precio de un activo este caería en niveles de sobrecompra, así como en caso contrario ante una baja del precio de un activo este caería en niveles de sobreventa.

Lo ocurrido en el año 2020 a causa del COVID19 como otras determinantes, fueron factores para que los tipos de cambio hicieran los movimientos que hicieron. Asimismo, una persona pudo haber operado estos activos con el uso de estas herramientas.

El uso de estas herramientas durante el 2020 en el USDMXN, GBPMXN y EURMXN pudo haber servido al inversionista para haber realizado operaciones tanto de compra como de venta y así, haber podido tener resultados positivos. Asimismo, mediante el uso de estas se pudo observar la dirección que tomaron los activos en varios momentos, en donde el movimiento de la apreciación de los tipos de cambio se dio cuando en marzo y abril del 2020 donde asimismo estos cayeron en niveles de sobrecompra; así también se vieron movimientos de aumento del precio de los activos cuando hubo sobreventa.

Estos modelos muestran entradas óptimas, pero no muestran puntos de salida, es por ello por lo que hay que entender que esta es una de sus limitantes, por lo que la persona interesada debe de tomar la decisión cuando salir de una operación y esto lo puede hacer bajo el criterio de cuanto espera de rendimiento, así como cuanto es el riesgo que estaría dispuesto a asumir. 


\section{Agradecimientos}

Se agradece rotundamente a los Apoyos de Estudios de Posgrado (PAEP) por parte de la Unidad de Posgrado de la Universidad Nacional Autónoma de México por el apoyo que se recibió para la realización de este trabajo de investigación.

\section{Referencias}

Chen, J. (11 de noviembre de 2020). Relative Strength Index. https://www.investopedia.com/terms/r/rsi.asp

Esquivel, G. (2020). Los impactos económicos de la pandemia en México The Economic Impacts of the Pandemic in Mexico. EconomíaUNAM, 17(51), 28-44. https://doi.org/10.22201/fe.24488143e.2020.51.543

Fama, E. (1960). Efficient market hypothesis. [Doctoral dissertation, University of Chicago]. The University of Chicago Library.

Guadilla, K. (2020). Análisis técnico: Sistemas automáticos de trading. [Trabajo de Grado, Universidad del País Vasco]. ADDI.

Gumparthi, S. (2017). Relative strength index for developing effective trading strategies in constructing optimal portfolio. International Journal of Applied Engineering Research, 12(19), 8926-8936. https:// doi.org/10.37622/000000

Hayes, A. (2 de noviembre del 2020). Stochastic Oscillator Definition.

https://www.investopedia.com/terms/s/stochasticoscilla tor.asp\#: :text=A\%20stochastic\%20oscillator\%20is\%2 0a,moving\%20average\%20of\%20the\%20result
Hernández, J. M. M., y Castro, A. M. (2020). El trading como profesión de emprendimiento considerando el FODA. Emprennova, 1(1), 53-65.

http://emprennova.uaq.mx/index.php/ojs/article/view/7

Lane, G. C. (1984). Lane's stochastics. Technical Analysis of Stocks and Commodities, 2(3), 80.

López, J. (6 de noviembre del 2020). Hipótesis del mercado eficiente.

https://economipedia.com/definiciones/hipotesis-delmercado-eficiente.html

Malkiel, B. G. (2003). The efficient market hypothesis and its critics. Journal of economic perspectives, 17(1), 59-82. https:// doi.org/10.1257/089533003321164958

Malkiel, B., y Fama, F. (1970). Efficient capital markets: A review of theory and empirical work. The journal of Finance, 25(2), 383-417. https://doi.org/10.1111/j.1540-6261.1970.tb00518.x

Monsalvo, J. (2019). Pronóstico del IPC en la BMV basado en el reconocimiento de patrones y análisis técnico utilizando datos diarios e intradiarios. [Tesis de Maestría, Universidad Nacional Autónoma de México]. Tesiunam.

Meneses-Bautista, F. D., y Alvarado, M. (2017). Pronóstico del tipo de cambio USD/MXN con redes neuronales de retropropagación. Res. Comput. Sci., 139, 97-110. https://www.rcs.cic.ipn.mx/2017_139/

Mercado Mexicano de Derivados. (7 de noviembre del 2020). Estadísticas. http://www.mexder.com.mx/ 
Murphy J. (1999). Technical Analysis of the Financial Markets. Primera edición. New York Institute of Finance.

Ni, Y., Liao, Y. C., y Huang, P. (2015). Momentum in the Chinese stock market: Evidence from stochastic oscillator indicators. Emerging Markets Finance and Trade, 51(sup1), S99-S110. https://doi.org/10.1080/1540496X.2014.998916

Preciado, V. H. T. (2020) La economía de la pandemia: efectos, medidas y perspectivas económicas ante la pandemia de la COVID-19 en el sector manufacturero de México. Contaduría y Administración, 65(4). http://dx.doi.org/10.22201/fca.24488410e.2020.3022

Serrano, F. (2014). Escuela de Bolsa. Manual de trading. Editorial Almuzara.

Serrano, F. (2019). Análisis técnico y bolsa para dummies. Planeta Libros.

Shleifer, A. (2000). Inefficient markets: An introduction to behavioural finance. OUP Oxford.
Ţăran-Moroşan, A. (2011). The relative strength index revisited. African Journal of Business Management, 5(14), 5855-5862.

https://doi.org/10.5897/AJBM.9000629

Tellaeche, J. R. (2020). Los retos de la economía mexicana: comercio, inversión extranjera, industria nacional y cambio tecnológico. EconomíaUNAM, 17(51), 404-417. https://doi.org/10.22201/fe.24488143e.2020.51.576

Valdecantos, E. D. (2016). El método Wyckoff: Claves para entender los fundamentos del trading. Profit Editorial.

Yahoo finance. (10 de noviembre del 2020). Historical data. Recuperado de https://finance.yahoo.com/

Wilder, J. W. (1978). New concepts in technical trading systems. Trend Research.

Wyckoff, R. D. (2006). How I Trade and Invest in Stocks and Bonds. Cosimo, Inc. 